\title{
POPULAR MUSIC EDUCATION IN AND FOR ITSELF, AND FOR 'OTHER' MUSIC: CURRENT RESEARCH IN THE CLASSROOM
}

\section{LUCY GREEN}

\begin{abstract}
This article considers some ways in which the school classroom enters into, changes and complicates musical meanings, focussing particularly on the role of popular music and how it relates to classical music. I suggest that in bringing popular music into the curriculum, educators have largely ignored the informal learning practices of popular musicians. Popular music has therefore been present as curriculum content, but its presence has only recently begun to affect our teaching strategies. I examine how the adaptation of some informal popular music learning practices for classroom use can positively affect pupils' musical meanings and experiences. This applies not only to the sphere of popular music, but also to classical music and, by implication, other musics as well. Finally, the notions of musical autonomy, personal autonomy and musical authenticity in relation to musical meaning and informal learning practices within the classroom are discussed.
\end{abstract}

Keywords: musical meaning, music classroom, informal learning, autonomy, authenticity, popular music, classical music

\section{Introduction}

The school classroom is a notorious site for the entanglement of musical meanings, values and experiences. Perhaps this is particularly so in relation to pupils' 'own' music - the popular field - as against what they often refer to as 'old people's music' - the classical field. In this essay I will first examine how the classroom itself changes and complicates musical meanings in relation to both popular and classical music.

Second, the notion of musical 'autonomy', the idea that music's 'true' meaning and value rise above mundane social and political considerations, is rightly discarded nowadays. ${ }^{1}$ Music is a part of everyday life, and must be understood as such. However, I will argue that there is a theoretical aspect of musical experience which is, momentarily, virtually free, or autonomous from the meanings of everyday musical experience. This aspect, which crosses over musical divisions and affiliations, can be reached in the classroom, particularly through informal music 
learning practices. Current research suggests that through such practices, pupils can reconceive not only popular, but also classical, and by extension other musics as well.

Third, popular music has at times been included in schools to pander to pupils' tastes, in the hope that this will lead them on to something more 'worthwhile' (that is, classical music). Such an approach implicitly downgrades the value of popular music in and for itself (Vulliamy 1977a and b; Green 1988). I will, however, suggest that such downgrading is not a necessary result of such approaches; popular music can be educationally valued, both for itself and in relation to its potential for leading pupils out into a wider sphere of musical appreciation.

Finally, I will suggest a link between musical autonomy and the personal autonomy of the learner. Through recognising both musical and personal autonomy, we can perhaps also throw light on some issues concerning musical authenticity, especially the role of authenticity within music education. I will suggest some ways of recognising autonomy and authenticity in the classroom, with the aim of easing the divide between popular and classical music that has continued to plague music education since the rise of the mass media.

\section{Musical meaning and experience: A brief overview}

I have written at length on the subject of musical meaning elsewhere, ranging in focus from musical ideology, musical value and issues of social class, to gender and the reproductive effects of music education (Green 1988, 1997; also see 1999, 2005b). Therefore here I will only briefly outline my theoretical position, which I will later apply for the purposes of the present article.

Music has meaning in so far as people understand it to be music in the first place: otherwise we would not be able to distinguish music from any other collection of sound and silence. It is helpful to conceive of musical meaning as involving two aspects, which exist in a dialectical relationship.

One aspect is what I refer to as 'inherent' meaning: the ways in which the materials that are inherent in music - sounds and silences - are patterned in relation to each other. This could be thought of as musical syntax, or inter- and intra-musical meaning. It is devoid of concepts or content in relation to the world 'outside' the music, but is a purely logical, or theoretical zone contained, or 'embodied' within the musical materials (Meyer, 1956). Whereas inherent musical meanings are made out of the materials of music, they arise from the human capacity 
to pattern sounds in relation to each other, which develops historically through both informal and formal exposure to music and musical activities.

The other aspect is what I call 'delineated' meaning. This refers to the extra-musical concepts or connotations that music carries, that is, its social, cultural, religious, political or other such associations. These may be conventionally agreed upon, such as the connotations of a national anthem for example; but they can also be unique to an individual, such as associating a particular song with a memorable moment. All music must carry some delineated meaning arising not only from its original context of production, but also from its contexts of distribution and reception. No music can ever be perceived as music in a social vacuum. Even music which is regarded as being autonomous, nonetheless carries the notion of its own autonomy as one of its prime delineations.

In all musical experience, both the inherent and the delineated aspects of musical meaning must occur, even though listeners may not be aware of them. For we could not notice any inherent musical meanings without simultaneously conceiving of a fundamental delineation: that what we are hearing is a recognised cultural object - a piece of music, an enactment or performance of some kind. Vice versa, we could not conceive of a piece of music unless we were already also ascribing some inherent meanings within it.

We may have positive or negative responses to either inherent or delineated meanings. Positive responses to inherent meanings are likely to occur when we have a high level of familiarity with, and understanding of the musical syntax. Positive responses to delineations occur when the delineations correspond, in our view, with issues that we feel good about. Musical 'celebration' is experienced when we are positively inclined both ways.

In contrast, negative experiences of inherent meanings arise when we are unfamiliar with the musical style, to the point that we do not understand what is going on, and thus find the musical syntax 'boring' (which is how many children say they feel about classical music). Negative responses to delineations occur when we feel that the music is not ours; for example, it belongs to social groups that we can't identify with (children often say that 'classical music is for 'old people', 'posh people' or 'show-offs'). Musical 'alienation' occurs when we feel negative towards both inherent and delineated meanings.

Our responses to inherent and delineated meanings usually correspond, so that if we dislike the one we will probably dislike the other, and vice versa. However, although I have suggested 
that inherent and delineated meaning must always co-exist, we do not always feel the same way about each of them. A person may be negative towards one aspect of musical meaning, whilst being simultaneously positive towards the other, engendering what I call 'ambiguity'. It is helpful to distinguish two types of ambiguity.

In one type, the experience of inherent meaning is negative, whilst that of delineated meaning is positive. For example, a person might be unfamiliar with the inherent meanings of Mozart because she has never played or sung Mozart and listens only rarely to his music. Therefore, she is relatively unable to recognise syntactical detail, formal, harmonic or rhythmic change, and hears the music as frilly, dull or superficial. But, at the same time, she enjoys the delineations in terms of the operatic plots, the social event of going out to the opera with friends, and so on.

In the other type of ambiguity, the experience of inherent meaning is positive, whilst that of delineated meaning is negative. We can think of the Mozart opera-goer who is totally familiar with the inherent meanings because of his classical background, having performed Mozart for many years. But he is critical of the operatic plots and dislikes going to the opera because he finds it 'stuffy'.

Not only may the quality of the response to one type of meaning contradict that of the other, but something else can occur, one of the most provocative aspects of music which raises interesting issues for music education: that the response to one aspect of meaning can overpower, influence and even change the other.

For example, the experience of delineation can override and influence that of inherent meaning. One late nineteenth-century Scandinavian music critic was in the habit of writing very positive reviews about a particular composer. Then he discovered that the composer was a woman. He still wrote positive reviews, but his language changed. Instead of saying 'strident', 'virile' or 'powerful', he began to use words like 'delicate' and 'sensitive'. The gender of the composer had entered the delineations of the music for this particular listener. His contemporary assumptions about gender, musical practice and compositional creativity were challenged. This new delineation then affected the way that the critic heard the inherent meanings (Green 1997).

On the other hand - and this is the central question that I now want to address - can the experience of inherent meaning override and influence that of delineation? The notion appears 
at first to be a logical impossibility, for inherent meaning is devoid of content, and cannot occur on its own. It exists as a theoretical, logical aspect of musical experience, which can only occur if there is also a delineated content. However, I will argue that experience of inherent meaning can indeed change, and challenge, our musical responses and presuppositions concerning delineation. Further, in this theoretical aspect of music's virtual autonomy from its social contexts, some of the most challenging questions and interesting possibilities arise, particularly for music education.

\section{Musical meaning and experience in the classroom}

Most music educators would agree that encouraging young children to experience as many styles and pieces of music as possible would be legitimate and indeed, highly desirable. As children grow up, and especially for those who go on to study music in Higher Education, we would certainly want to encourage some critical distance, so that celebration could give way to a more balanced judgement, allowing considered responses and evaluation of different musics in relation to a variety of criteria. But achieving such criticality is more likely to occur if pupils' ears have already been opened, through positive experiences of a variety of musics in relation to both inherent and delineated meanings; that is, through what I have referred to as musical celebration.

Most music educators would probably also agree that the response of pupils to music in the classroom is sadly unenthusiastic. The most successful and inspiring music teachers tend to be among the first to suggest that music education does not reach all pupils. Many pupils have 'ambiguous' experiences, or worse, 'alienated' experiences resulting from negativity towards the inherent and the delineated meanings of much classroom music. The reasons are not straightforward .

First, let us consider delineation in the classroom. In the post-second world war period, it was unthinkable that popular music, jazz or any other vernacular form, apart from Western folk music, could be brought into a classroom in the UK, North America, Australia or many other countries in which a Western style of music education prevailed. This was partly because the delineations of such music were, and continue to be, associated with issues such as teenage rebellion, sexuality, drugs, and so on. Pupils were educated in Western classical music and folk music, mainly through singing and listening. Thus, they were required to study music with whose delineations they largely had no point of identification. 
Second, let us consider inherent meaning in the classroom. Pupils tend to be unfamiliar with the inherent meanings of classical and folk musics. Whilst folk music in some countries, (usually those who have been colonised), has a stronger presence in family and social life across the generations, folk music in many other countries, especially ex-colonial powers such as the UK or Japan, has more negative delineations in the social and political climate. For many children, as well as teachers, it has taken on the mantle of museum culture (e.g. Green 2002b, Endo 2004). Overall, listening to classical and/or folk music is simply not a part of the cultural practices of most school children. Without repeated listening, stylistic familiarity cannot develop, and without some stylistic familiarity, positive experience of inherent meaning is unlikely to occur.

In general, pupils in the post second-world war period were likely to be in a negative relationship to both the delineated and the inherent meanings of music in the classroom, and thus, alienated. As a response, educators began introducing music which pupils could be expected to welcome. Popular music and jazz, along with what is unfortunately now known as 'world music', were accepted into the curriculum very slowly from the end of the 1960s until their formal inclusion within a number of countries towards the end of the century. ${ }^{2}$ Today there is a great variety of such music in many curricula (e.g. Green 2002b, Lundquist and Szego 1998; Campbell 1991; Volk 1998).

One could therefore suppose that pupils should no longer be particularly negative towards the delineations or the inherent meanings of music in the classroom. However musical meanings are slippery modes of communication. One cautionary point is that popular music remains a broad category. For children of school age, not only does 'popular music' change every few weeks, but there is evidence that some pupils conceal their 'real' musical tastes when at school, in favour of appearing to be a part of the mass mediated music of the Top 40. This may be particularly so in the case of children from minority cultures. ${ }^{3}$ It is therefore reasonable to suggest that mass music provides a 'safe', if not always authentic, cultural space which pupils can inhabit, and behind which they can conceal private cultural identities.

But the situation is more complex still. Let us consider delineation. As I have suggested (above; Green 2005a; 2005c), social context already forms a part of music's delineations. Therefore, as soon as any music is brought into a new context of reception, its delineations are apt to change. Indeed, when popular music is introduced into the classroom, its very presence often means that it ceases to be considered as 'pop music' by the pupils. Pupils have often told me that their curriculum contains only 'classical music'; whilst their teacher and the 
departments' Scheme of Work make it perfectly clear that the curriculum contains a variety of popular, jazz, traditional and world musics. Most teachers would be likely to agree that so far as pupils are concerned, the Beatles belong to the classical realm. Even teachers who include up-to-date popular music cannot reasonably change their curriculum materials at a speed which reflects pupils' changing allegiances. So music which carries positive delineations for pupils inside the classroom is hard to come by, and even harder to sustain as curriculum.

One could allow pupils to bring in their own music; however, what should we do with it then? Consider this question in relation to popular music's inherent meanings in the classroom. In spite of the mounting enthusiasm with which popular music has been greeted (see note 2), once inside the classroom it tends to be treated by teachers, exam boards and National Curricular requirements, largely as though its inherent meanings warranted the same kinds of attention as those of classical music (Green 2002a, 2002b). Not only is this musicologically dubious (see e.g. Middleton 1990), but, as Vulliamy observed many years ago, analysing popular music, and treating it as curriculum knowledge defied pupils' taste (Vulliamy 1977a and b). In the words of one Year 9 student in Paula Jackson's recent doctoral research, 'It becomes like classical music when we do it in school' (Jackson 2005). Further, not only may the classroom context change delineation, but as I have suggested, delineation can influence our experience of inherent meanings. This happened to the Scandinavian critic once he knew the music had been composed by a woman. So pupils' taken-for-granted familiarity with the inherent meanings of mass popular music is not, on its own, enough to engender a positive experience of them in class.

Music may well take on new, problematic delineations inside the classroom; these may in turn negatively affect responses to its inherent meanings; and on top of that, pupils' familiarity with popular music's inherent meanings is likely to turn sour if those meanings are approached in formal educational ways. In short, while popular music has been present in the classroom for many years, identification with its delineations, and familiarity with its inherent meanings have not led to experiences of 'musical celebration' for overwhelming numbers of school children. Thus, many pupils tend to find themselves in an ambiguous or even alienated relationship to much classroom music, even when it is music that celebrates them outside the school.

\section{Popular music, meaning and practice in the classroom}

We have seriously overlooked something. One of the strongest, if perhaps implicit, delineations transmitted by popular music is the notion that its musicians acquire their skills and knowledge without any apparent need for education in the first place! It has been a central 
part of musical ideology from rock to hip hop, soul to reggae, that the music is a direct, unmediated and authentic expression of feeling, untrammelled by the dictates of convention, and arising naturally from the 'soul' of the musicians. In my current research, when 13 to 14 year-old pupils were asked how popular musicians acquire their skills and knowledge, two exemplary answers were: 1) 'They just play what they feel and stuff'; and 2) 'They get a guitar, and they go up to their bedroom'. Some children did also suggest that, for example, 'They practice' and 'They get lessons'. However none of them showed any awareness of more fundamental and essential popular music learning practices. While it is increasingly true that some popular musicians take formal lessons and even degrees in popular music nowadays, all popular musicians must engage in what have come to be known as informal learning practices. These differ greatly from formal music educational procedures and from the ways in which classical musical skills and knowledge have been acquired and transmitted, at least over the last two centuries or so (Green 2002a).

It is helpful to identify five main characteristics of informal music learning practices, along with some of the ways in which they are distinguished from formal music education. First, informal learners choose the music themselves, music which is already familiar to them, which they enjoy and strongly identify with. In formal education, teachers usually select music with the intent to introduce learners to areas with which they are not already familiar. Second, the main informal learning practice involves copying recordings by ear, as distinct from responding to notated or other written or verbal instructions and exercises. Third, not only is the informal learner self-taught, but crucially, learning takes places in groups. This occurs through conscious and unconscious peer-learning involving discussion, watching, listening to and imitating each other. This is quite distinct from the formal realm, which involves adult supervision and guidance from an expert with superior skills and knowledge. Fourth, informal learning involves the assimilation of skills and knowledge in personal, often haphazard ways according to musical preferences, starting with whole 'real world' pieces of music. In the formal realm, pupils follow a progression from simple to complex, which often involves a curriculum, syllabus, graded exam, specially composed piece or exercises. Finally, throughout the informal learning process, there is an integration of listening, performing, improvising and composing, with an emphasis on creativity. Within the formal realm, there is more of an emphasis on reproduction.

So, production of the inherent meanings of popular music seems devoid of the kinds of skills and knowledge normally associated with long and arduous study, such as those appropriate for a music education within the classical sphere. Perhaps it is this that has in the past 'deafened' 
many music educators and musicologists to the specific properties of popular music's inherent meanings. Like the Scandinavian critic, one could suggest, musicologists for much of the twentieth century allowed their understanding of the delineations of popular music to influence their perceptions of its inherent meanings. New musicologists have been developing new analytic criteria that are more suited to the inherent meanings of vernacular musics (e.g. Middleton 1990; Walser 1993; Brackett 1995; Ford 1997; Moore 2002), and such approaches may now be starting to enter the school. But to reiterate: analysis of popular music is not likely to engage school pupils in the classroom; and in any case, analysis bears no resemblance to how popular musicians actually learn to produce the music themselves.

How are we to bring a cultural form into an education system, when that cultural form proclaims its own independence from education? And not only how, but what for? Until recently popular music's presence in the classroom has been restricted to a change of curriculum content. In developing this new content, we have focussed mainly on the music itself - the product - and have largely failed to notice the processes by which this product is transmitted in the world outside the school. Thus the changes we have made in our curriculum content lacked any corresponding change in our teaching strategies. This point is crucial, because the ways in which music is produced and transmitted give rise to the nature of its inherent meanings, as well as its different delineations. If its authentic production and transmission practices are missing from the curriculum, and if we are unable to incorporate them into our teaching strategies, we will be dealing with a simulacrum, or a ghost of popular music in the classroom, and not the thing itself. Positive experience of both delineated and inherent musical meanings will thus continue to slip out of the classroom so far as pupils are concerned, and an opportunity to engage pupils, not only in popular music but in music per se may have been lost.

\section{Informal learning practices in the music classroom: some current research}

The main aims of my current research are to investigate the problems and possibilities of bringing some aspects of informal music learning practices into the secondary music classroom. This work, which is on-going, is supported by a large number of organisations and individuals, to whom I owe an enormous debt of acknowledgement and thanks. Details of how the work was done, teaching materials, and further examination of our findings to date can be found in other publications, although there is still much more to be done. ${ }^{4}$

The project has taken, and is taking, place in 21 schools so far, although the data here come from only eight of them: one pre-pilot and three pilot schools in London, and four main study 
schools in Hertfordshire. In each school we focussed on one Year 9 class (age 13-14). The project involves a series of teaching and learning strategies, each of which attempts to replicate two or more of the characteristics of informal popular music learning suggested above; that is: 1) allowing learners to choose the music; 2) learning by listening and copying recordings; 3 ) learning in friendship groups with minimum adult guidance; 4) learning in personal, often haphazard ways; 5) integrating listening, playing, singing, improvising and composing.

The first stage of the project, which contains the essence of the approach, draws on the first four of the above characteristics. Pupils were asked to bring their own CDs, form small friendship groups, take the CDs into a practice space and choose one song (songs being the only genre that pupils brought in). They then had to copy the song aurally from the recording as a group, using their own choice from a selection of instruments. The teacher was to spend much less time than usual teaching, and more time standing back. Teachers observed and attempted to empathise with the goals that pupils set for themselves; they then diagnosed problems, and only later offered guidance for pupils to watch and imitate if so desired.

What happens when a group of 13 and 14 year olds are told they can go into a room with several of their own CDs, a CD player, a selection of instruments, and copy a chosen song in any way they wish? All of the teachers, myself and the other project team members included, were apprehensive. But we have been consistently and pleasantly surprised. Here for example, is an annotation from a recording of a group of five boys in an inner city London school in their second lesson. There was no teacher in the room, and the boys were not aware that they were being recorded. (They later gave their permission for the recording to be used in research. $)^{5}$

David and John's group are apparently mucking around. It sounds like chaos. Someone is playing something on the piano, nothing to do with the chosen song. The radio is put on. There is random drumming and talking.

David and John's group 10 minutes later, still having had no teacher input. Something is emerging; John is working out the notes of the song on the piano (D E D E D E D E in a syncopated rhythm in the right hand, with a downwards-moving bass answering the upper melody in the left hand). Someone is playing the snare drum, trying to keep to the same rhythm as John. Discussion is occurring. Someone is singing along to the piano pitches. 
A further 20 minutes later: you can hear the guitar now, and the opening has been organised. There is a beat using floppy sticks on the rim of the snare. Listening and counting are evidently occurring:

-John: How many beats are there?

Inaudible discussion.

-David: Hey you guys, I'm playing it now.

More inaudible talk.

-Rahul: Hurry up.

-John: How many beats, how many beats are there?

-Rahul: Sixteen.

-John: It's either 16 or 32 .

At the end of the lesson, the group gave a performance to the rest of the class, in which the drum-kit played a 16-beat opening in a quasi-rock style, finishing with a crash on the ride cymbal. Along with this the guitar played a melody of the opening notes as indicated above. At the ride cymbal crash the piano entered for a repetition of the melody, now played in unison with the guitar. There was hand percussion with pauses at appropriate structural moments.

There was a sense of vitality in the playing, and we observed an air of serious concentration on the faces of the boys, who afterwards expressed considerable pride in what they had achieved.

How did these pupils move, with very little guidance or supervision, from apparent chaos to something musically organised and celebratory? Many answers emerged, and I have chosen to present three here.

First, I would like to consider the notion of 'natural learning process'. While first attempting to copy their chosen song, in several groups including the one above, the percussion played along with the rhythm of the vocal line or main melody, rather than the rhythm of the percussion. For example, in another concealed recording of a group of five girls in a different school, the kitdrummer can be heard attempting to play the rhythm of the lead vocal line of Jennifer Lopez's hit 'My Love Don't Cost A Thing'. During the second lesson an explicit beat emerges, then disappears. At one point there is some discussion of whether the drums ought to be playing a beat. Gradually something approximating to a rock beat emerges. By the end of the third lesson, the drummer is playing a basic rock beat with an occasional habaňera rhythm inserted into it. She plays with sensitivity, marking structural moments with an up-beat figuration, and enhancing occasional climactic moments with a hit on the ride cymbal. The idea of a beat, and the use of the drums to mark structural features came to this group, and indeed most of the 
groups, naturally and without any teaching. This raises several questions, including whether children in general would tend to hear the relationship between percussion, melody, beat and structure in a similar progression.

Second, there are issues of group ensemble and listening to each other. We have several examples of children playing together in time to a common beat, while one of them is playing on the beat but in the wrong part of the bar - for example, playing one beat 'out' with everyone else. There are also examples of children playing together, but with one or more persons simply in a different time-zone to everyone else. If this happened classical musicians would be bound to stop and start again. But in this informal classroom situation the pupils carry on. In fact they go on and on without stopping, for several minutes at a time. This tendency to keep going and to avoid correcting raises all sorts of questions concerning the concepts of 'flow' and pleasure, co-operation, the kinds of aims that this kind of music-making entails, and its differences from the worlds of formal education and classical music.

Third, the project raises questions about the role of the teacher. With several groups, children began the first lesson by playing and singing quite accurately and well in time together, but in many cases there seemed to be a dip in about the second or third lesson, when they got 'worse' in various ways. In such situations our conventional duty as teachers has been to offer help. However, the role of the project teachers was to stand back and observe. To the surprise of all the project teachers, after a dip the pupils would 'right' themselves without our input. They also progressed much further than expected. As one Head of Music said, 'In a normal class I am working so hard, I am just making such an effort; they're not working nearly as hard as I am. In this class, they're doing the work; they're learning.' In this way, the project has both raised the expectations of many of the teachers concerning their pupils' capacities, and called into question whether progression sometimes involves what may be a natural process of getting worse before getting better.

At the end of the activities we interviewed groups of pupils in the three pilot and four main study schools. One of the strongest responses concerned motivation, enjoyment and relevance. Here are a few comments:

-I'd prefer music if it was like this for like the whole of school.

-This way we can actually learn about music. 
-This is more like the sort of thing you're going to need when you're older - like how to play an instrument rather than just how to read notes and stuff.

-I thought it was good, it was fun, it was a challenge and I enjoyed it, I really enjoyed it.

-It's well fun - it's probably our best lesson so far.

-It's unlike any other lesson that we've done before.

We asked pupils what they thought of the fact that they were 'thrown in the deep end' without any help from teachers. Nearly everyone agreed that not being taught was part of the fun. Some said it would have been 'nice' if they received more help from the teachers. However, further investigation revealed that many of these meant it was nice to have help when it was wanted, but not when it wasn't:

-John: ...let's say you're learning, let's say you're in a band and have to do what we did or create a song, (inaudible) send us into a practice room and gives us some instruments and we can get on with it ourselves, and then if we had any problems, he could tell us how to solve things and we can learn it that way. By trial and error ... -Researcher: And you feel that that's a good way of learning, do you? -John: Well, yeah. 'Cause you can learn what mistakes you made.

-Wesley: I think that's a better way. So, we tried to handle it ourselves but if we can't do it someone will help us.

Many others implied that not being taught was educationally beneficial. For example:

-You can learn more by yourself; you can experiment; there's no-one telling you it's wrong; you can't do nothing wrong.

-It teaches you that you can learn music on your own, you don't need a teacher telling you what to do.

-If you teach yourself, you feel better, 'cause you realise that like you've done it all by yourself. 
-I've learnt that if you haven't got any goals set for you, you've got to find some yourself.

-I've learnt more in this than I did in the whole of music last year.

Many pupils identified improvements in their listening abilities. We asked: 'Since you have been doing the project, have you noticed any differences in the ways that you listen to music, say if you are watching TV or something at home?' Some looked bemused and shook their heads (although there are some interesting reasons for this which there is no space to examine here). Several immediately and forcefully said 'yes'. For example:

-I've been listening to music recently and I've like kind of picked up the different rhythms and stuff.

-I think I listen to more the instruments now than the actual words.

-I listen more to the beat more than the lyrics ... I think [inaudible] we were really concentrating on the, like, rhythm and the beat of that song, and now, to me, like, in songs, the rhythm and that stands out more than ... I don't really take any notice of the words.

-I listen to the instruments whilst playing in the background. Before I used to watch the musicians, see how they dance (laughs). Now as I listen to it - the instruments, how they're playing in the background - I try to figure out what instrument they use.

Among other findings, several pupils identified co-operation as a learning outcome.

-Josh: I think I've learnt to, like, work more as a team, like listen to each other, whereas before like I used to like always be speaking over everyone kind of thing -

-Researcher: Really?

-Josh: Yeah but I've like got used to working as a group now better.

-Sam: ... before we was like told what to do, this time like we didn't have to, we done it our own way -

-Muhammed: We done it ourselves.

-Sam: Yeah.

-Muhammed: We didn't have no teachers with us either. 
-Josh: And we chose to go in the group, we wasn't told to, so we probably enjoyed it more and listened to each other.

Teachers unanimously identified music-listening as the main skill that developed, along with ensemble playing, instrumental and rhythmic skills. They were also unanimous that motivation and enjoyment were significantly higher than normal, and were surprised to find group cooperation better than usual. They estimated that most pupils, notably those who are normally disaffected, applied themselves to the task all, or nearly all of the time. One teacher said he was 'shocked' by the high levels of co-operation and application. A major factor in all this, it was felt, was the greater freedom and responsibility invested in the pupils. Teachers also agreed that whilst at first they found it hard to stand back, they learned about their pupils' abilities and characteristics by doing so.

For the next four to six lessons pupils continued to listen and copy, firstly using structured materials taken from a funk song, 'Word Up' by Cameo. The song was broken down into separate riffs, so that each riff could be heard and played along with independently, making the task of listening and copying much easier. The riffs could then be combined within the studentgroup to form their own version of the song. Following this, pupils (in the main study schools only) had a second opportunity to choose a song to copy, then for the rest of the spring term they wrote their own songs in bands, with occasional input from visiting musicians.

\section{Informal learning practices and classical music: The litmus test}

That took us to the next major challenge: the introduction of classical music. We wished to build on the increased motivation and the skills acquired so far, and to continue the informal learning practice of listening and copying in friendship groups, but now drawing pupils away from what they already knew and into the wider world of music. My hypothesis was that through a direct and positive engagement with the inherent meanings of music whose delineations were negative, pupils would experience that potential of musical autonomy which I posited at the beginning of this essay: that theoretical aspect of musical meaning, in which inherent meaning virtually frees itself from the narrowing straits of previously unquestioned delineations, which can thus reveal themselves as contingent and capable of changing.

Pupils were asked to listen to, choose, and copy a piece of music from a CD selection representing the core of the classical canon - pieces by Bach, Handel, Brahms, Clara Schumann, Puccini, Strauss, Borodin, Satie, and one contemporary piece played on 'classical' instruments, by the Penguin Café Orchestra. Six of the ten pieces were likely to be familiar to 
the pupils through contemporary television advertisements or common knowledge (such as Strauss's ‘Also Sprach Zarathustra' from a Kellog's Cornflakes commercial, or Beethoven's 'Für Elise', the opening of which is regularly picked out on keyboard instruments by thousands of school children every term, at least in the UK). The other four pieces were completely unknown to pupils (such as the last movement of Brahms' first symphony). Pupils undertook the exercise twice for three lessons each time. The first time they were given five pieces, all from TV commercials, and asked to choose one and copy it with no structured guidance. The second time they were given 'Für Elise' and four other of the more obscure pieces. This time they had guidance from the $\mathrm{CD}$, on which the recording of each original piece was followed by a simplified version in two parts, then independent, repeated 4 to 8-bar segments of the melody and bass parts, as with the funk song earlier in the year.

'Miss, can we have another CD? This one's all classical!', and 'Miss, why are all the songs slow?' were among the first responses. Pupils had left us in little doubt about their views of classical music, or at least, the views they were prepared to express in school and in front of peers. This is not to belittle the importance of that context and those peers, for it is precisely through social context and interaction that musical delineations take on content and significance. Below is an excerpt from an interview conducted at the end of the exercise. It illustrates pupils' views of classical music, and also how, for these and many other pupils, those views began to change as they worked, through the informal learning practice of listening and copying, on the inherent meanings of classical music.

-Researcher: ...how do you think you would describe your views of classical music before you did this?

-Bobby: I didn't like it at all.

-Joe: It's not really my thing.

-David: It's pretty boring.

-Bobby: Yeah.

-David: Classical music is like -

-Ahmed: Old people.

-David: Yeah, this thing again, you're like... It's just boring. It does my ear in.

-Matthew: It's just repeated over and over again.

-David: Yeah, pretty much.

-Researcher: Right, OK. So what was your response when you first listened through to the CDs?

-Matthew: Oh no! 
-David: Pretty boring. Didn't really want to know 'cause it's like classical music, like, [yawns] I might as well fall asleep....

-Researcher: Erm, how do you feel about the music that you chose and that you worked on?

-David: Well, 'cause we didn't really know about it, we didn't really know what it was about, and it was pretty boring. But now, I've progressed and know how to play it a bit, which is pretty cool.

-Researcher: So, you don't think it's so boring now, is that what you're saying?

-David: Not at the moment.

-Matthew: It's boring when you don't know how to play the tunes, but once you know how to play the tunes it's like -

-Bobby: It's good.

-David: It's cool.

-Matthew: 'Cause you can actually get on.

-Bobby: I wouldn't say it's as cool as like normal music.

-David: Nah, it ain't as street as like rap or hip hop....

-Matthew: Before I thought it was rubbish because our grandparents listen to it.

-Researcher: So what's changed?

-Bobby: Well we've learnt to play it kind of thing.

-Matthew: We've added our own sort of new bits in it.

-Bobby: And made it better.

-Ahmed: And you get used to it.

Some other examples, each taken from a different group interview, are:

-Maybe we don't like listening to it, but as you do it yourself you're like really proud of yourself, saying 'Yeah, I can do classical music', erm maybe I won't listen to it on the radio or whatever, but I'll still do stuff with it.

-Before we did this I didn't really like classical music. I'd still listen to it but not for a long time. And like, as, I think my views have changed because like I can have a little bit of joy in playing it - now that I know like how to do stuff.

-If you don't really like classical you can get to like it really, 'cause you can experience doing it. 
-Before we started the classical project we didn't think it was as appealing to listen to classical music, but as we went on with the project we saw that people must have had a lot of talent, a lot of practice to be able to play the pieces. So it's a lot more appealing than it was before

-Yeah, it's like, like originally we personally would have thought that the people playing the music are like, no offence, but a bunch of show offs really, cause like they were playing all the really complicated bits. But as it goes on, and as you're trying to play it yourself, you're like 'oh you must have talent to be able to play something like that'.

-Now I've listened to a bit more I see that it takes a lot more work to try and do classical music than it does like the pop music. 'Cause most of the pop music they've all got like the same drum beat and things like that, where classical music is totally different.

-Normally if I heard classical I'd just turn it off straight away, but I probably would actually listen to it now if it was on the radio.

\section{The pop/classical split: Meaning, autonomy and authenticity in the music classroom}

Can the theory of musical meaning and experience that I expressed earlier shed any light on the project's findings? I have argued that the distinction between the inherent and delineated aspects of musical meaning is purely theoretical. When we actually engage with music the two aspects of meaning come to us experientially as one unified whole. We do not usually, and often cannot, distinguish them. Such an entanglement is by no means unique to musical experience. For example we can theoretically distinguish between different types of love: sexual love, parental love, filial love, love between siblings, love between friends, and so on. We can also make distinctions between other cognate areas, for example liking, desire, lust. But experientially it is not always easy to separate these feelings from one another, and indeed, that difficulty leads to a great deal of confusion and complexity in our lives. Yet that does not mean that we give up the idea of making the distinctions theoretically, for there are so many cases in which they are clear and helpful.

Because of the difficulty in distinguishing experientially between the two aspects of musical meaning, they appear to be entangled. Thus delineated meanings appear to be a part of the inherent meanings - of the 'music itself'. Our responses to delineations therefore seem 
unquestionable. The inherent meanings appear to contain the delineations, as if the delineations do really reside immutably inside the music. The delineations seem to be immediate, that is, un-mediated by history and convention, not constructed, but natural, unquestionable and 'true'.

I have suggested that the classroom context has a tendency to change pupils' perceptions of music's delineations, and that the delineations of popular music do not fit well in the classroom. Additionally, popular music's inherent meanings have been rather distorted by a pedagogy that has been slow to recognise the demands of popular music's informal learning practices. Contrastingly, those of classical music match very well with pupils' associations of classical music with work, studiousness, boredom, old people (read: teachers), irrelevance, and removal from everyday life. But such delineations do not end there; they also affect pupils' perceptions of classical music's inherent meanings - confirming that these also really are as boring as they seem!

This is where I wish to reclaim the notion of musical autonomy. By paying attention to how children learn informally in music, whether it is applied to popular or classical or any other music, I wish to suggest, we allow an engagement with musical inherent meanings as a theoretical aspect of virtual musical autonomy from social contexts. When they engage with music's materials themselves, especially through aural, informal learning practices, pupils are touching on an aspect of inherent meaning which is virtually freed for a moment from social context. They are bringing inherent meanings into being and are able to imbue the music with a new delineated content of their own. They touch a quality of musical experience which, precisely because of its fleeting freedom from delineation, at the same time exposes the inevitability of delineation. Previous assumptions about classical music being, say, old and boring, or about any other musical delineation, are then able to surface. The delineations are made audible as historical contingencies, rather than as fixed and immutable parts of the 'music itself'. Then new delineations, new conceptions become possible. It is through such experiences of inherent meanings as theoretically separable from delineation, and thereby open to any content, that new musical and social horizons can appear. The potential freedom, or autonomy, of such content from previously taken-for-granted assumptions and definitions is thus exposed. In that moment appears the glimmer of an alternative reading.

In the case of popular music, to which school children are already generally positively inclined, such an experience simply makes the inherent meanings available to them - 'Look, I can do this!'. The delineations are then less likely to be negated by the demands of the classroom, but can belong once more to the pupils. But the litmus test of this theory is the pupils' responses to 
a music whose delineations they decry. In working directly with the inherent meanings of classical music through informal learning practices, many pupils in our project experienced positive changes in their musical responses. Informal learning practices, now applied in some measure to classical music's inherent meanings, resulted, through that theoretical aspect of virtual musical autonomy, in changing pupils' understanding of not only the music's inherent meanings but also its delineations. So, to give a short answer to the question that I raised earlier: can the experience of inherent meaning override and influence that of delineation? Yes, I believe so.

\section{Autonomy and authenticity in the music classroom}

Before the project started, several teachers were concerned about issues of musical authenticity in the classroom, particularly in relation to the pupils' 'own' culture of popular music. The lack of authentic popular music instruments would, teachers feared, be problematic. They also felt that the technical difficulty of replicating professionally produced music would be off-putting. Pupils would consider their own products inferior and, therefore, inauthentic. But there was no suggestion that pupils were as concerned about the authenticity of their musical products as adults expected them to be. I wonder whether the problem of authenticity in the classroom is an adult construction, caused by too much focus on the product, and, as Christopher Small argued so long ago (1980), not enough on the process of music-making.

Perhaps we should aim, not for the authenticity of the musical product, but for the authenticity of the musical learning practice; in other words, not for 'musical authenticity' but more for 'music-learning authenticity'. In the case of popular music, this would involve changing pedagogy so as to approach popular music's inherent meanings in ways that are more authentic to how the music is actually created. There has always been a problem of authenticity in the classroom with relation to classical music too. Indeed, no ordinary class of mixed-ability children is likely to be able to play any kind of music in a way that is musically authentic. Again, the learning practices of classical musicians have also been removed, over the last hundred years, from their original contexts. They too, used to be much more informal, deeply located within musician-family or apprenticeship networks, whereby young learners acquired their skills and knowledge by immersion in an adult community of practice. Perhaps we have gone too far in removing these practices into an 'inauthentic' realm of formal educational principles and procedures.

Finally, I want to connect the two concepts, of 'musical autonomy', and 'music-learning authenticity', to the concept of the 'personal autonomy' of the learner. This is because some 
attention to informal learning practices within music education could offer pupils a level of autonomy from their teachers, which would increase their capacity to carry on their learning independently. Thus, this would encourage further participation in both formal and informal music-making beyond the school. Furthermore, as our findings suggest, practical involvement with musical inherent meanings through aural copying naturally leads to an enhancement in the ability to listen to music. Once ears have been opened, they can hear more. When they hear more, they appreciate and understand more. As I argued earlier, the greater the familiarity, the more positive the experience of music's inherent meanings, and there is no better way to gain familiarity than by playing or singing music oneself. Pupils can thus be celebrated by music in the classroom, through positive experiences of both inherent and delineated meanings, accessed via an authentic engagement in relation to musicians' real-world aural practices, and to how children and young people learn music. Beginning with pupils' own, self-selected music, and using learning practices that come relatively naturally to them, pupils can be lead out: e-ducated.

In summary, if we employ informal music learning practices in the classroom, at least some of the time, it will help us to enhance the authenticity of the learning experience, allowing learners to 'get inside' the inherent meanings of music, freed for a moment from specific, and therefore limiting, delineations. Learners can imbue music with their own, alternative, delineations. Music's apparently immutable, fixed and 'true' delineations - about the nature of the music itself, the people who made the music, the people who listen to it, their social, political or religious values, beliefs and actions - are challenged. Precisely by acknowledging music's theoretical aspect of virtual autonomy from social contexts, we can appreciate how readily music becomes filled with social content and significance. By allowing learners the personal autonomy to explore authentically that aspect of musical autonomy, we open their ears to the possibility of imbuing music with a much wider variety of delineations than children and young people usually realise are available. In so doing we also make available a new wealth of responses not only to music, but also to the social, cultural, political and ideological meanings that music carries.

\section{NOTE}

This article is a shortened and slightly different version of my inaugural professorial lecture, Meaning, autonomy and authenticity in the music classroom; 2005, the Institute of Education, University of London. 


\section{References}

Alden, A. (1998). 'What does it all mean? The National Curriculum for Music in a multicultural society'. Unpublished MA dissertation, Institute of Education, University of London.

Bennett, A. (2000). Popular music and youth culture: Music, identity and place. London \& New York: MacMillan Press.

Brackett, D. (1995). Interpreting popular music. Cambridge: Cambridge University Press.

Campbell, P. S. (1991). Lessons from the world: A cross-cultural guide to music teaching and learning. New York: Schirmer Books.

Clayton, M., Herbert, T. \& Middleton, R. (2003). The cultural study of music: A critical introduction. New York \& London: Routledge.

De Nora, T. (2000). Music in everyday life. Cambridge: Cambridge University Press.

--(2003). After Adorno: Rethinking music sociology. Cambridge: Cambridge University Press.

Dunbar-Hall, P. (1996). 'Designing a teaching model for popular music'. In Gary Spruce (Ed.). Teaching music. London \& New York: Routledge in association with the Open University.

Dunbar-Hall, P. \& Wemyss, K. (2000). 'The effects of the study of popular music on music education'. International Journal of Music Education, 36, 23-35

Elliott, D. J. (1995). Music matters: A new philosophy of music education. Oxford University Press.

Endo, Y. (2004). 'Japanese Identity Formation through Japanese Traditional Instrumental Music'. Unpublished MA dissertation, Institute of Education, University of London.

Ford, C. (1997). 'Robert Johnson's rhythms'. Popular Music, Vol. 17, no. 1. PAGES? 
Gammon, V. (1999). 'Cultural politics of the English National Curriculum for Music, 19911992'. Journal of Educational Administration and History. Vol. 31, no. 2. PAGES?

Goehr, L. (1992). The imaginary museum of musical works: An essay in the philosophy of music. Oxford: Clarendon Press.

Green, L. (1988). Music on deaf ears: Musical meaning, ideology and education. Manchester $\&$ New York: Manchester University Press.

-- (1997). Music, gender, education. Cambridge: Cambridge University Press.

-- (1999). 'Research in the sociology of music education: some fundamental concepts'. Music Education Research, Vol.1, no. 2, 159-169.

-- (2002a). How popular musicians learn: A way ahead for music education. London \& New York: Ashgate Press.

-- (2002b). 'From the Western classics to the world: secondary music teachers' changing perceptions of musical styles, 1982 and 1998'. British Journal of Music Education, Vol. 19, no. 1, 5-30.

-- (2005a). 'Musical meaning and social reproduction: A case for retrieving autonomy'. Educational Philosophy and Theory, Vol. 37, no. 1, 77-92.

-- (2005b). 'The music curriculum as lived experience: Children's "natural” music learning processes', Music Educators' Journal. Vol. 91, no. 4, 27-32.

--(2005c). ', Meaning, autonomy and authenticity in the music classroom, (an inaugural professorial lecture); Institute of Education, University of London

Green, L. and Walmsley, A. (2006a), 'KS3: Musical Futures’, by Lucy Green and Abigail Walmsley, in Classroom Music, Vol. 2, no. 3, pp. 19-25

Green, L with Walmsley, A. (2006b). The Informal Music Classroom at Key Stage 3: a practice-based research and curriculum-development project, Teaching materials and resources including a CD-ROM documentary film; Paul Hamlyn Foundation, London 
(Forthcoming, April 2006)

Ho, W. (1999). 'Political Transition and Politicization of Hong Kong Secondary Music Education', Music Education Research. Vol 1, no. 2 PAGES?

Jackson, P. (2005). 'Secondary school pupils' conceptions of music in and out of school: conforming or conflicting meanings?'. Unpublished $\mathrm{PhD}$ thesis, Institute of Education, University of London.

Leppert, R. \& McClary, S. (Eds.). (1987). Music and society: The politics of composition, performance and reception. Cambridge: Cambridge University Press.

Lundquist, B. \& Szego, C. K. (1998). Music of the world's cultures: A source book for music educators. Perth: International Society for Music Education.

Martin, P. (1995). Sounds and society: Themes in the sociology of music. Manchester \& New York: Manchester University Press.

Maryprasith, P. (1999). The effects of globalisation and localisation on the status of music in Thailand. Unpublished Ph.D thesis, London University Institute of Education.

Meyer, L. B. (1956). Emotion and meaning in music. Chicago \& London, University of Chicago Press.

Middleton, R. (1990). Studying popular music. Milton Keynes: Open University Press.

Moore, A. (2002). Rock: The primary text: Developing a musicology of rock. London \& New York: Ashgate Press, (second edition).

Rodriguez, C. (Ed.). (2004). Popular music and education. USA: Music Educators' National Conference.

Shepherd, J. \& Vulliamy, G. (1994). 'The struggle for culture: a sociological case study of the development of a national music curriculum'. British Journal of the Sociology of Education, Vol. 15, no. 1. PAGES? 
Small, C. (1980). Music - society - education, London: John Calder.

Swanwick, K. (1992). Music education and the national curriculum. The London File: Papers from the Institute of Education, London: The Tufnell Press.

Volk, T. (1998). Music, education, and multiculturalism: Foundations and principles. New York: Oxford University Press.

Vulliamy, G. (1977a). 'Music and the mass culture debate' in John Shepherd, Paul Virden, Trevor Wishart \& Graham Vulliamy (Eds.). (1977), Whose music: A sociology of musical language. London: Latimer New Dimensions.

Vulliamy, G. (1977b). 'Music as a case study in the "new sociology of education"“, in John Shepherd, Paul Virden, Trevor Wishart \& Graham Vulliamy (Eds.). (1977), Whose music: A sociology of musical language. London: Latimer New Dimensions.

Vulliamy, G. \& Lee, E. (Eds.). (1976). Pop music in school. Cambridge: Cambridge University Press.

-- (1982) Pop, rock and ethnic music in school. Cambridge: Cambridge University Press.

Vulliamy, G. \& Shepherd, J. (1984a) 'The application of a critical sociology to music education'. British Journal of Music Education, Vol. 5, no. 1. PAGES?

Wemyss, K. L. (1999) 'From T. I. to Tasmania: Australian indigenous popular music in the curriculum'.Research Studies in Music Education, no. 13, December. PAGES?

Walser, R. (1993) Running with the devil: Power, gender and madness in heavy metal music. Hanover \& London: Wesleyan University Press.

\section{Notes}

${ }^{1}$ See e.g. Clayton et al (2003), De Nora (2000, 2003), Middleton (1990), Goehr (1992), Martin (1995), Elliott (1995) or Leppert \& McClary (1987).

${ }^{2}$ Scandinavian countries are probably among the first and most far-reaching in this respect. For history, information, critical accounts and arguments concerning the entrance of popular music 
into the curriculum in the UK, see e.g. Swanwick (1968); Vulliamy (1977a and b); Vulliamy \& Lee (1976; 1982); Green (1988); Shepherd \& Vulliamy (1994); Swanwick (1992); Gammon (1999); and for Australian, US-American, Hong Kong and Thai perspectives respectively, Wemyss (1999); Dunbar-Hall \& Wemyss (2000); Dunbar-Hall (1996); Rodriguez (2004); Ho (1999); Maryprasith (1999).

${ }^{3}$ For example see Bennett (2000) on the complexities of globalisation and localisation in relation to ethnic and social class identities and musical taste among young people; also see Alden (1998) with relation to young children, musical taste and ethnicity; and there are of course gender issues surrounding children's concealment or revealing of musical taste, for which see Green (1997).

${ }^{4}$-Further information, sound-bites of children's products, and up-dates about the national project of which this work is a part are available on the website: www.musicalfutures.org A preview of the teaching materials is available in Green and Walmsley (2006a); the materials themselves will shortly be available in Green with Walmsley (2006b). Amongst many others, I would like to thank Abigail Walmsley, our Research Officer and Project Manager, for her invaluable, insightful and extensive contribution to this research; John Witchell for having invited me to work with the Hertfordshire Music Service, and for his enthusiasm and support throughout; David Price and the Paul Hamlyn Foundation for including the work in their national 'Musical Futures' project and for their unfaltering support; Hilary Hodgson and the Esmée Fairbairn Foundation for believing in the work in its early stages, and for their continuing support; the Department for Education and Skills Innovation Unit for support; the Heads of Music and many other music teachers in Hertfordshire and London, who have put heart and soul into trying out the teaching strategies in their classrooms; and of course, the children for being so inspiring and rewarding. Further information and up-dates about the national project of which this work is a part are available on the website: www.musicalfutures.org.uk.

${ }^{5}$ Some of the data below are also considered in Green (2005b). 